\title{
Novel method for evaluation of anaerobic germination in rice and its application to diverse genetic collections
}

\author{
Noriyuki Kuya $^{1)}$, Jian Sun ${ }^{1,2)}$, Ken Iijima ${ }^{1)}$, Ramaiah Venuprasad ${ }^{3)}$ and Toshio Yamamoto*1,4) \\ 1) Institute of Crop Science, National Agriculture and Food Research Organization (NARO), 2-1-2 Kannondai, Tsukuba, Ibaraki 305- \\ 8518, Japan \\ 2) Rice Research Institute of Shenyang Agricultural University, Shenyang 110161, China \\ 3) Africa Rice Center (AfricaRice), c/o IITA, PMB 5320, Ibadan, Nigeria \\ 4) Institute of Plant Science and Resources, Okayama University, 2-20-1 Chuo, Kurashiki, Okayama 710-0046, Japan
}

\begin{abstract}
Direct seeding saves time and labour in the cultivation of rice. However, seedling establishment is often unstable, and yields are lower than in transplanting. Anaerobic germination (AG) is a key trait for improvement of direct seeding of rice. We established a simple and reliable method of evaluating AG in rice breeding. We germinated seeds in distilled water or deoxygenated water and measured coleoptile length several days later; compared the results of each method with survival rate in flooded soil; and used the anoxic water method for QTL analysis and for testing cultivars. Coleoptile elongation in anoxic water and survival rate in flooded soil were significantly correlated $(r=0.879, P<0.01)$. A significant QTL, likely to be a major gene $(A G 1)$, was found in chromosome segment substitution lines and in a backcrossed $\mathrm{F}_{2}$ population derived from tolerant and sensitive lines. Diverse rice genetic resources were classified into tolerant or sensitive accession groups reflecting their ecotypes. Our study revealed that anoxic water evaluation method saves space and time in a stable environment compared with flooded soil evaluation. It is applicable to QTL analysis and isolation of genes underlying anaerobic germination.
\end{abstract}

Key Words: rice, anaerobic germination, anoxic water, direct seeding, QTL, genetic resources, phenotyping method.

\section{Introduction}

Unplanned flooding poses a serious constraint in the cultivation of rice around the world, especially in sub-Saharan Africa, where it regularly afflicts as much as one-third of the rainfed lowland rice areas. In 2008, an estimated $5 \%$ of farmers there experienced flooding, which affected $37 \%$ of their land and reduced production by $27 \%$ (Diagne et al. 2013). Flooding during germination and early growth can lead to total crop failure. Therefore, rice tolerant to flooding during germination and early growth is needed.

Rice seeds can germinate without oxygen (Atwell et al. 1982, Perata et al. 1997), unlike other major cereals such as wheat (Alpi and Beevers 1983, Perata et al. 1997), oat (Alpi and Beevers 1983), and barley (Perata et al. 1997), because it can make its enzyme for starch degradation without oxygen (Guglielminetti et al. 1995). This trait, called anaerobic

Communicated by Ryuji Ishikawa

Received January 16, 2019. Accepted August 1, 2019.

First Published Online in J-STAGE on October 4, 2019.

*Corresponding author (e-mail: yamamo101040@okayama-u.ac.jp) germination (AG), can decrease the damage by submergence during germination and is particularly important for rice cultivation in Africa, where most rice farmers sow by direct seeding. Surveys of genetic factors responsible for AG show a wide phenotypic variation in survival rate under flooding (Ismail et al. 2009, Miro and Ismail 2013). Among QTLs for AG detected (Angaji 2008, Angaji et al. 2010, Baltazar et al. 2014, Septiningsih et al. 2013), qAG-9-2 was narrowed down to the gene $A G 1$ (Os09g0369400, OsTPP7) (Kretzschmar et al. 2015). AG1 belongs to the trehalose-6phosphate phosphatase gene family and works to elongate the coleoptile under submergence. However, the biological mechanism of $A G$ is still unclear.

In spite of the many reports of QTLs for AG in rice, so far only $A G 1$ has been identified. The explanation is that $\mathrm{AG}$ is a complex trait affected by dormancy, maturation, and seed storage conditions after harvest. Therefore, the establishment of a method to evaluate AG is a key to success. In the isolation of $A G 1$, QTLs from an IR64/Khao Hlan On// IR64 backcross population were first detected through the use of a flooded soil evaluation method (Angaji et al. 2010). This method reflects actual environmental conditions but is 
affected by the soil physical state, temperature changes in the greenhouse, water conditions in submergence, light conditions, and soil nutrients, so it is difficult to replicate conditions across experiments. In addition, it needs a large space and takes at least 3 weeks. Thus, positional cloning of the genes responsible is tough work. Although distilled-water evaluation methods are also used (Hsu and Tung 2015, 2017, Zhang et al. 2017), the correlation between their indexes of germination and survival rates in flooded soil have not been confirmed yet.

Here, we established a novel method for evaluating AG in anoxic water. This method saves space and time in a stable environment compared with flooded soil evaluation. To test its effectiveness, we used it to survey phenotypic variation in $\mathrm{AG}$ within an experimental crossing population, in a diverse rice collection and in accessions of $O$. glaberrima, which offer potential genetic resources for future rice breeding.

\section{Materials and Methods}

\section{Genetic resources}

We acquired seeds of the AG-tolerant 'Ma-Zhan (Red)' and 'Khao Hlan On' from the International Rice Research Institute (IRRI) Genebank. We collected seeds from the World Rice Core Collection (WRC, 69 accessions) (Kojima et al. 2005), the Rice Core Collection of Japanese Landraces (JRC, 50 accessions) (Ebana et al. 2008), the AG-tolerant 'Arroz da Terra' and 109 accessions of $O$. glaberrima in the National Agriculture and Food Research Organization (NARO) Gene bank. Among these, we could not use immature seeds caused by late flowering (by $\sim 15$ September), leaving 57 WRC, 35 JRC, 'Arroz da Terra' and 13 O. glaberrima accessions (Supplemental Table 1). These plants were grown in a paddy field of NARO in Tsukuba, Japan $\left(36^{\circ} 01^{\prime} \mathrm{N} 140^{\circ} 06^{\prime} \mathrm{E}\right)$, from 2014 to 2017 . From these materials, 8 accessions ('Ma-Zhan (Red)', 'Khao Hlan On', 'Deng Pao Zhai', 'IR64', 'Jarjan', 'Naba', 'Koshihikari' and 'Arroz da Terra') were initially used for flooded soil evaluation reflecting actual environmental conditions, anoxic water evaluation as our new method and distilled water evaluation as control followed by correlation analysis. Other seeds were used only in anoxic water evaluation after confirmation of its effectiveness.

In addition, we used a set of chromosome segment substitution lines (CSSLs) derived from $O$. sativa ssp. japonica 'Koshihikari' $\times$ ssp. indica 'IR64' (Koshihikari background and IR64 background) (Nagata et al. 2015), and an $\mathrm{F}_{2}$ population $(n=96)$ of IR64 $\times$ SL2130, one of the CSSLs with a Koshihikari genome segment at $6.79-19.94 \mathrm{Mb}$ on chromosome (Chr.) 9 in the IR64 background. The plants of CSSLs were grown in a paddy field of NARO in Miraidaira $\left(36^{\circ} 00^{\prime} \mathrm{N}, 140^{\circ} 00^{\prime} \mathrm{E}\right)$, Japan, in 2014 . The $\mathrm{F}_{2}$ plants were grown in a paddy field of NARO in Tsukuba, Japan, in 2017.

\section{Seed preparation}

Harvested seeds were dried immediately at $30^{\circ} \mathrm{C}$ in a drying oven for 4 days, desiccated at room temperature for about 2 months, held at $50^{\circ} \mathrm{C}$ for 5 days to break dormancy, and finally stored at $4{ }^{\circ} \mathrm{C}$ for 2 to 24 months, as seed age and storage condition affect anaerobic germination (Ella et al. 2010). Since $O$. glaberrima had stronger dormancy, those seeds were kept at room temperature about half year after harvest before breaking dormancy.

Accessions with a low germination rate even in the best conditions $(<90 \%$ in flooded soil and $<80 \%$ in anoxic water, described later) were not used in the experiments (Supplemental Table 1). To remove the effect of seed dormancy, we assessed seed germination under normal conditions every day; if most seeds germinated after $>3$ days of incubation, we did not use that accession.

\section{Flooded soil evaluation}

We installed a flooded soil evaluation system in a greenhouse with reference to IRRI (Angaji et al. 2010, Septiningsih et al. 2013). First, nursery soil was dried and then sieved at $2.5 \mathrm{~mm}$. The soil was placed in 16-well trays (each well $6.5 \mathrm{~cm}$ square). The trays were submerged in water and the soil was mixed thoroughly with tweezers to remove all air. The next day, 20 high-quality imbibed seeds $\left(4^{\circ} \mathrm{C}, 2\right.$ days in distilled water) per well were buried under the soil $(2 \mathrm{~cm}$ depth) by tweezers. The trays were then placed in a large container in which water was added to a depth of $20 \mathrm{~cm}$. We kept the water depth at $20 \mathrm{~cm}+/-3 \mathrm{~cm}$ during the experiment. The water temperature was maintained at $30^{\circ} \mathrm{C}$ by heaters for 3 weeks. The number of seedlings that emerged out of the water surface at 21 days was counted. The percentage out of 20 seeds was defined as survival rate (SR).

\section{Anoxic water evaluation}

The method of anoxic water evaluation is shown in Fig. 1. We prepared anoxic water by adding $0.6 \%(\mathrm{v} / \mathrm{v})$ Oxyrase, a commercial enzyme product used to remove dissolved oxygen (Oxyrase Inc., Mansfield, OH, USA), to distilled water, which was then incubated at $30^{\circ} \mathrm{C}$ overnight. We decreased the amount of used OXYRASE from 2\% $(\mathrm{v} / \mathrm{v})$ described in the manual to $0.6 \%(\mathrm{v} / \mathrm{v})$, because this concentration was enough to make anoxic water in our experimental condition. The resultant dissolved oxygen level was $<0.3 \mathrm{mg} \mathrm{L}^{-1} \mathrm{O}_{2}$ as measured with a dissolved oxygen meter (SG6, Mettler Toledo, Schwerzenbach, Switzerland). We added $50 \mathrm{~mL}$ of anoxic water to $50-\mathrm{mL}$ vials $(34 \times 90 \mathrm{~mm})$, put 20 imbibed seeds $\left(4^{\circ} \mathrm{C}, 2\right.$ days $)$ in the water and closed the lid tightly. The seeds were incubated at $30^{\circ} \mathrm{C}$ in the dark for 5 to 7 days depending on accession and population. After incubation, the seeds were aligned and photographed with a digital camera (K-5 IIs, Pentax, Tokyo, Japan). The coleoptile length of all seeds was then measured in ImageJ software (NIH, Bethesda, MD, USA). 


\section{Correlation analysis}

To confirm effectiveness of anoxic water evaluation against actual phenotype of $\mathrm{AG}$, we calculated coefficients of correlation between average coleoptile length in both anoxic and distilled water evaluations and SR by flooded soil evaluation. When we conduct distilled water evaluation, we added $60 \mathrm{~mL}$ of distilled water to $60-\mathrm{mL}$ longer vials $(27.5 \times 140 \mathrm{~mm})$, put 20 imbibed seeds $\left(4^{\circ} \mathrm{C}, 2\right.$ days $)$ in the water. The dissolved oxygen level of the water was 6-7 mg L $\mathrm{m}^{-1} \mathrm{O}_{2}$. The seeds were incubated in the dark for 5 days in the distilled water. The lids of the vials were opened during incubation. Additionally, to confirm that the observed coleoptile elongation is specific only in anaerobic condition, we calculated coefficients of correlation between these factors and either coleoptile (CLc) or shoot lengths (SLc) of seeds incubated on wet filter paper in a Petri dish in the dark for 5 days.

\section{Application of anoxic water evaluation to genetic analysis}

We used 12 SSR markers showing polymorphism between Koshihikari and IR64 (Supplemental Table 2) on Chr. 9 for genotyping. Total DNA was extracted from 2-month-old seedlings by the cetyltrimethylammonium bromide method (Murray and Thompson 1980). PCR mixture $(5 \mu \mathrm{L})$ contained $1 \mu \mathrm{L}$ template DNA $\left(10 \mathrm{ng} \mu \mathrm{L}^{-1}\right), 2.5 \mu \mathrm{L}$ $2 \times$ KAPA2G Fast Ready Mix (Kapa Biosystems), $0.075 \mu \mathrm{L}$ each of forward and reverse primer $(10 \mu \mathrm{M})$, and $1.35 \mu \mathrm{L}$ $\mathrm{H}_{2} \mathrm{O}$. Initial denaturation was conducted for $1 \mathrm{~min}$ at $95^{\circ} \mathrm{C}$. Amplification was performed for 35 cycles of $10 \mathrm{sec}$ at $95^{\circ} \mathrm{C}, 10 \mathrm{sec}$ at $55^{\circ} \mathrm{C}$, and $1 \mathrm{sec}$ at $72^{\circ} \mathrm{C}$, followed by $30 \mathrm{sec}$ at $72^{\circ} \mathrm{C}$. The amplified products were separated by electro-

Imbibition and selection of seeds (distilled water, $4{ }^{\circ} \mathrm{C}, 2$ days)

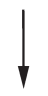

Preparation of anoxic water $\left(0.6 \% \mathrm{v} / \mathrm{v}\right.$ Oxyrase, $30^{\circ} \mathrm{C}$, overnight $)$

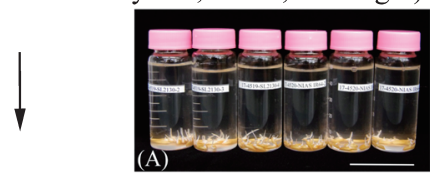

Sowing (50 $\mathrm{mL}$ anoxic water in vials, $30^{\circ} \mathrm{C}, 5-7$ days)

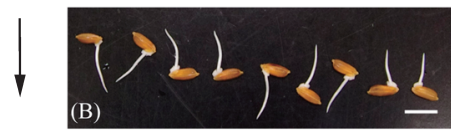

Photographing

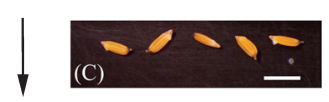

Measurement of coleoptile elongation (ImageJ)

Fig. 1. Anoxic water evaluation method. (A) Seeds in vials. Bar $=5 \mathrm{~cm}$. (B) Coleoptiles of tolerant $O$. sativa 'Dahonggu'. Bar $=1 \mathrm{~cm}$. (C) Coleoptiles of sensitive $O$. sativa 'Surjamukhi'. Bar $=1 \mathrm{~cm}$. phoresis in 3\% agarose gels at $200 \mathrm{~V}$ for $45-70 \mathrm{~min}$ Construction of linkage map and QTL analysis were performed in QTL IciMapping software (Meng et al. 2015).

Comparison of coleoptile elongation under anoxic condition among ecotypes

We compared the WRC and JRC accessions by their ecotypes as classified by Ebana et al. (2010): TrJ I-III, $O$. sativa tropical japonica groups I-III $(n=6)$; Ind II-III (indica), O. sativa indica $(n=19)$; Ind I (Aus), O. sativa Aus $(n=20) ; O g, O$. glaberrima $(n=8), \operatorname{TrJ} \mathrm{I}, O$. sativa tropical japonica group I $(n=6)$; TeJ, $O$. sativa temperate japonica group $(n=16)$.

\section{Statistical analysis}

To compare coleoptile lengths under anoxic water among cultivar groups, we used the $t$-test and Tukey's HSD test. The correlations between SR and each incubation treatment were evaluated using Pearson's product-moment correlation coefficient. These analyses were conducted by JMP v. 7.0 software (SAS Institute, Cary, NC).

\section{Results}

\section{Flooded soil evaluation}

The AG-tolerant 'Ma Zhan Red' (Septiningsih et al. 2013) had a survival rate (SR) of 70\% and 'Khao Hlan On' (Angaji et al. 2010, Kretzschmar et al. 2015) had an SR of 40\% (Fig. 2). The AG-sensitive IR64 (Angaji et al. 2010, Kretzschmar et al. 2015) had an SR of $12 \%$. Although harvest year of the seeds of Koshihikari and Arroz da Terra is different from other accessions, the trend of SR was similar between their reports and ours. Therefore, we conclude that our flooded soil evaluation was appropriate. Other cultivars, Naba, Deng Pao Zhai, and Jarjan had SRs of 58, 12, and $0 \%$, respectively.

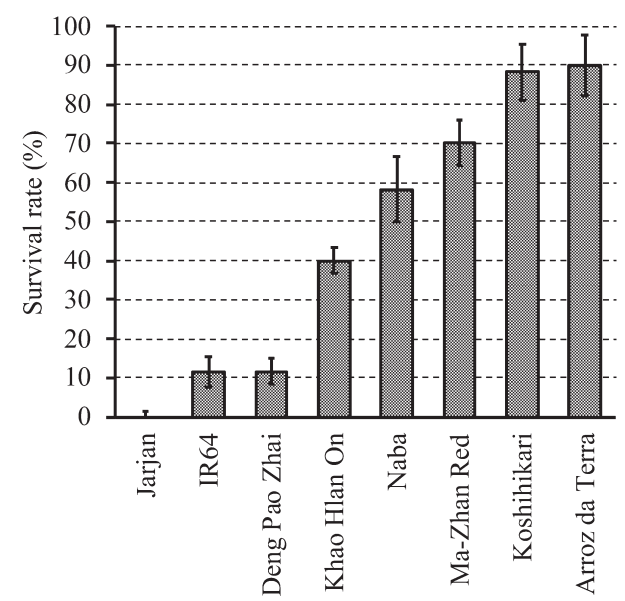

Fig. 2. Survival rates of representative cultivars in flooded soil evaluation system ( $2 \mathrm{~cm}$ depth). Values are mean $\pm \operatorname{SD}(n=3)$. 


\section{Anoxic water evaluation}

SR had a high correlation with coleoptile length in anoxic water $(r=0.879, P<0.01)$ and with coleoptile length in distilled water $(r=0.742, P<0.05$; Table 1). On the other hand, it had no significant correlations with control shoot length $(-0.425)$, and control coleoptile length (0.038).

\section{Application of anoxic water evaluation to genetic analysis}

Among the Koshihikari $\times$ IR64 CSSLs, SL2031, with an IR64 genome segment at $10.70-21.38 \mathrm{Mb}$ on Chr. 9 in the Koshihikari background, had significantly less coleoptile elongation than Koshihikari (Supplemental Figs. 1, 3A, $30^{\circ} \mathrm{C}$, 5 days). On the other hand, SL2130, with a Koshihikari genome segment at 6.79-19.94 Mb on Chr. 9, had significantly more coleoptile elongation than IR64 (Supplemental Figs. 2, 3B, $30^{\circ} \mathrm{C}, 6$ days). This result implies that a QTL involved in AG lies on the overlapped region (10.70 $19.94 \mathrm{Mb}$ ). To confirm this, we evaluated coleoptile elongation of the $\mathrm{F}_{2}$ population of IR64 $\times$ SL2130 in anoxic water

Table 1. Coefficients of correlation between coleoptile or shoot length under each condition and survival rates in the flooded soil evaluation system

\begin{tabular}{cclrl}
\hline \hline Condition & $\mathrm{AN}$ & $\mathrm{DW}$ & $\mathrm{SL}_{\mathrm{C}}$ & $\mathrm{CL}_{\mathrm{C}}$ \\
\hline $\mathrm{DW}$ & 0.593 & & & \\
$\mathrm{SL}_{\mathrm{C}}$ & -0.354 & 0.180 & & \\
$\mathrm{CL}_{\mathrm{C}}$ & 0.117 & 0.381 & 0.527 & \\
$\mathrm{SR}$ & $0.879^{* *}$ & $0.742 *$ & -0.425 & 0.038 \\
\hline
\end{tabular}

$\mathrm{AN}$, anoxic water; $\mathrm{DW}$, distilled water, lid open; $\mathrm{SL}_{\mathrm{C}}$, control shoot length; $\mathrm{CL}_{\mathrm{C}}$, control coleoptile length. ${ }^{* *} P<0.01,{ }^{*} P<0.05(n=3)$.

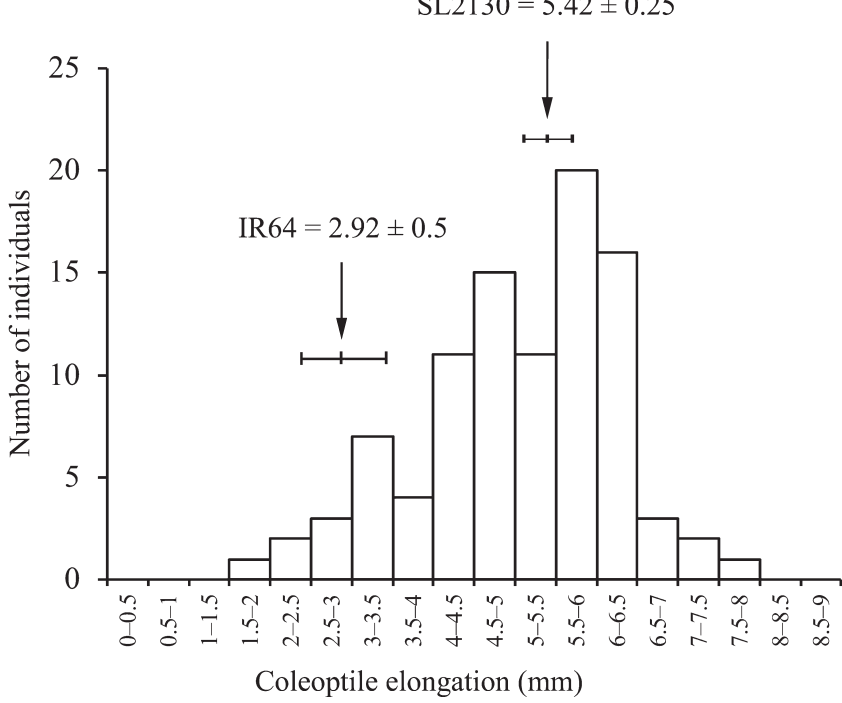

Fig. 3. Frequency distribution of coleoptile length of $F_{3}$ seeds of $F_{2}$ population of IR64 $\times$ SL2130 (mean, $n=3$ ). Seeds were evaluated in anoxic water. $\left(30^{\circ} \mathrm{C}, 6\right.$ days). The coleoptile elongation of SL2130 was $5.42 \mathrm{~mm}$, while that of IR64 was $2.92 \mathrm{~mm}\left(30^{\circ} \mathrm{C}, 6\right.$ days $)$, and the frequency distribution in the $\mathrm{F}_{2}$ population was continuous (Fig. 3). One significant QTL peak was detected between RM1896 (11.8 Mb) and RM24162 (12.3 Mb) (Table 2). The logarithm of the odds (LOD) score of this QTL was 19.87, the phenotypic variation explained (PVE) was $64.3 \%$, and the additive effect was $-1.37 \mathrm{~mm}$ (Koshihikari allele increases). The $A G 1$ (Os09g0369400) gene locus (12.25 Mb) lies in this region (Kretzschmar et al. 2015). There is no $A G 1$ gene in the IR64 genome because of deletion of the gene locus (Kretzschmar et al. 2015). On the other hand, we confirmed that the $A G 1$ gene sequence of Koshihikari is same with that of Nipponbare (data not shown).

Anoxic water evaluation of WRC accessions and Oryza glaberrima

Coleoptile elongation of $O$. sativa 'Dahonggu' $(9.4 \mathrm{~mm})$, 'Davao 1' (9.3 mm), and 'Pinulpot 1' (9.0 mm) was high, but that of $O$. sativa 'Kaluheenati' $(0.10 \mathrm{~mm})$, 'Shoni' (0.14 mm), and 'Surjamukhi' (0.15 mm) was low (Fig. 4A). That of most $O$. glaberrima $(\mathrm{Og})$ accessions was low except for O. glaberrima 'TOG 5923' (2.63 mm) (Fig. 4B). Among ecotypes, coleoptile elongation of $O$. sativa tropical japonica (TrJ I-III) tended to be high, but that of most $O$. sativa indica I (Ind I: Aus) and O. glaberrima $(O g)$ tended to be low (Fig. 4C).

\section{Anoxic water evaluation of JRC accessions}

Coleoptile elongation of $O$. sativa 'Shiroine' (10.3 mm), 'Houmanshinden Ine' (9.3 mm), and 'Akamai' (JRC 40) $(8.8 \mathrm{~mm})$ was high, but that of $O$. sativa 'Karahoushi' (0.04 mm), 'Okkamodoshi' (0.42 mm), and 'Akamai' (JRC 21) $(0.60 \mathrm{~mm})$ was low (Fig. $5 \mathbf{A}, 30^{\circ} \mathrm{C}, 5$ days). That of $O$. sativa temperate japonica (TeJ) elongated much better than that of O. sativa tropical japonica I ( $\mathrm{TrJ}$ I) (Fig. 5B).

\section{Discussion}

This study was designed to establish a simple and reliable method of AG phenotyping for use in rice breeding. SR as determined by the standard method of evaluation in flooded soil was significantly correlated with coleoptile elongation as evaluated in anoxic water $(r=0.879, P<0.01$ : Table 1$)$. SR also had a significant correlation with coleoptile length in distilled water $(r=0.742, P<0.05)$ although the significance level was lower than in anoxic water. Thus, anoxic water evaluation enables us to conduct accurate phenotyping for AG tolerance. On the other hand, it had no correlation with control shoot length $(-0.425)$, and control coleoptile

Table 2. QTL detected in IR64/SL2130 $\mathrm{F}_{2}$ population

\begin{tabular}{ccccccc}
\hline \hline Chromosome & \multicolumn{1}{c}{ Marker physical interval (Mb) } & LOD & PVE (\%) & Add. & Dom. \\
\hline 9 & RM1896 (11.8) & RM24162 (12.3) & 19.87 & $64.3 \%$ & -1.37 & -0.01 \\
\hline
\end{tabular}

$\mathrm{LOD}=$ logarithm of odds; PVE = phenotypic variation explained; Add. = additive effect; Dom. = dominant effect. 
(A)

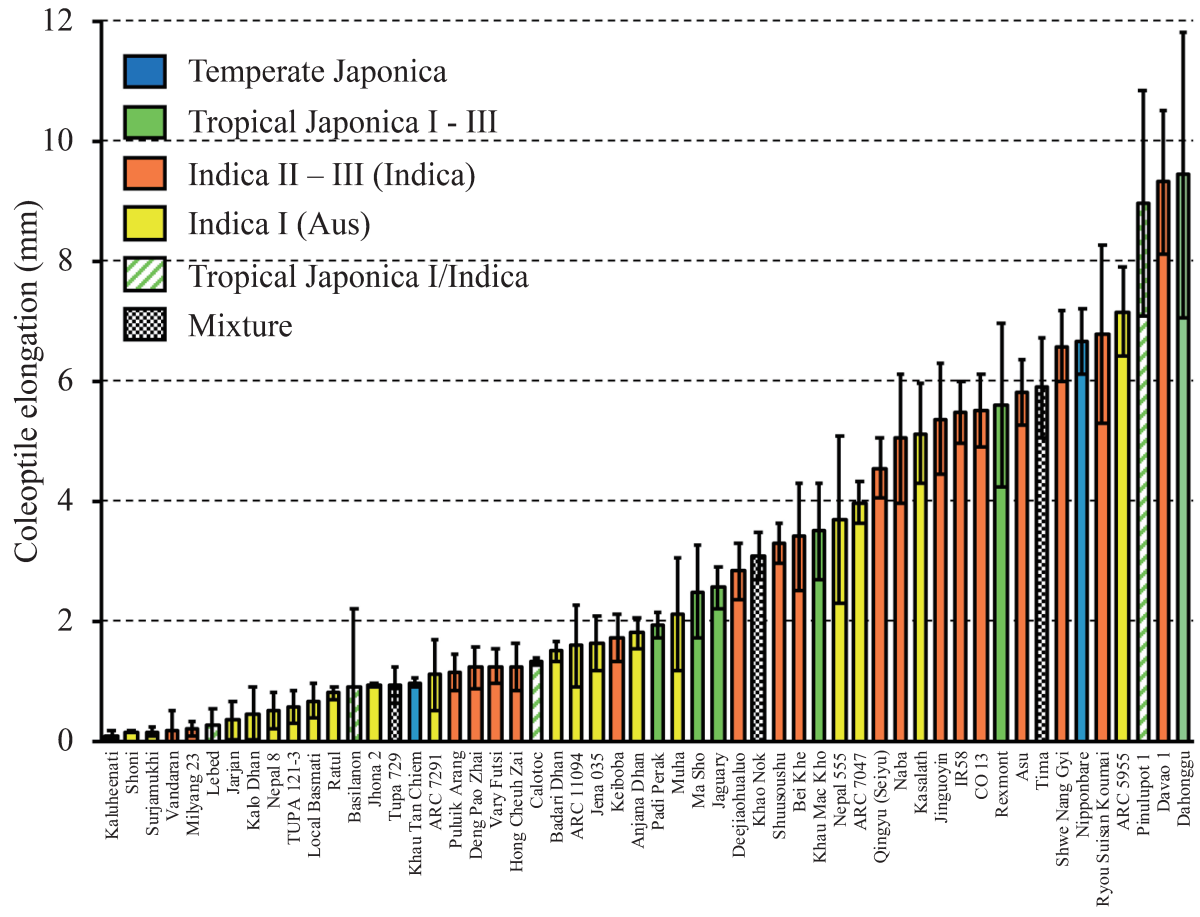

(B)
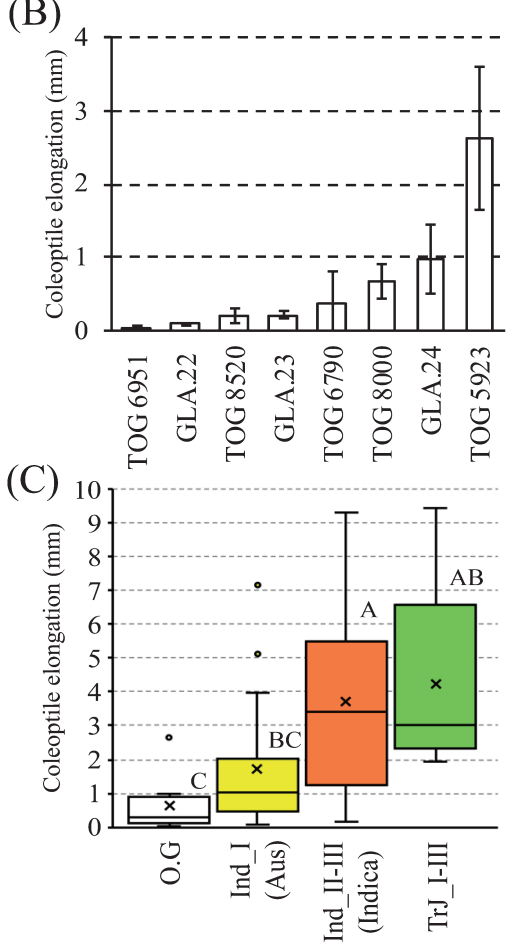

Fig. 4. Coleoptile elongation under anoxic conditions: (A) World Rice Core Collection (WRC); (B) O. glaberrima accessions (mean $\pm \mathrm{SD}$, $n=3$ ). (C) Box plots of WRC groups (mean \pm SD). Box plots with the same letter are not significantly different by Tukey's HSD test $(P<0.05)$. $O g$, O. glaberrima $(n=8)$; Ind I (Aus), $O$. sativa Aus $(n=20)$; Ind II-III, $O$. sativa indica $(n=19)$; TrJ I-III, $O$. sativa tropical japonica I-III $(n=6)$.

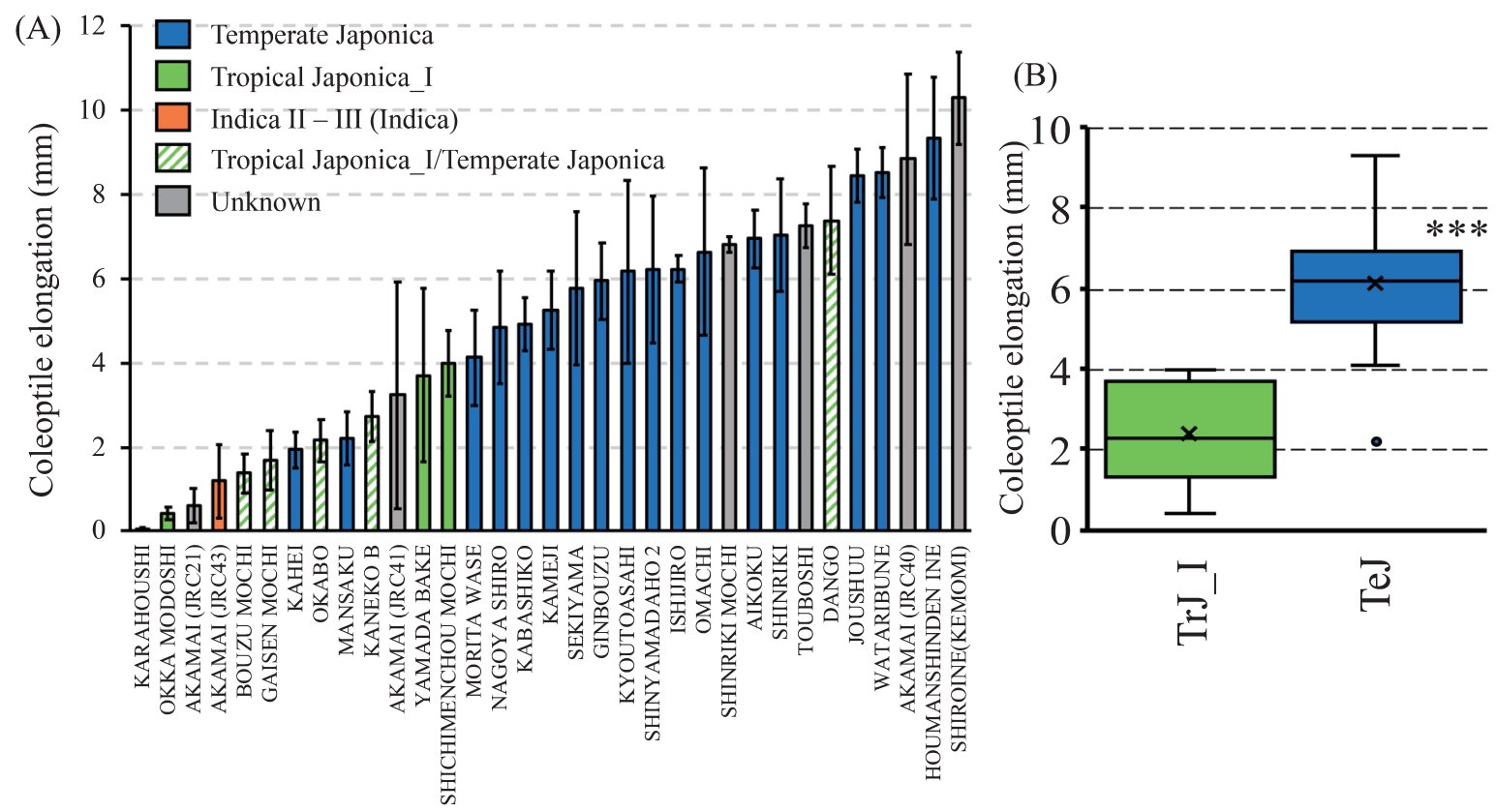

Fig. 5. Coleoptile elongation under anoxic conditions: (A) Coleoptile elongation of Rice Core Collection of Japanese Landraces (JRC) under anoxic conditions (mean $\pm \mathrm{SD}, n=3$ ). (B) Box plot of JRC groups (mean $\pm \mathrm{SD}$; *** $P<0.001, t$-test). TrJ I, O. sativa tropical japonica group I $(n=6)$; TeJ, O. sativa temperate japonica $(n=16)$.

length $(0.038)$. These results implied that there is the specific mechanism of the coleoptile elongation under anoxic and hypoxic condition. The anoxic water method also confirmed the location of the $A G 1$ locus (Table 2) (Angaji et al. 2010, Kretzschmar et al. 2015). These results suggest that the anoxic water evaluation method can be used in large-scale 
genetic analysis.

When we conduct genetic analysis of quantitative traits, material conditions and experimental conditions have to be controlled. AG is a complex trait affected by seed harvest and storage conditions. Furthermore, it is difficult to replicate experimental conditions in the flooded soil evaluation method. In contrast, the anoxic water evaluation method is suitable for genetic analysis because it requires no soil, and the seeds are evaluated at a fixed temperature. In addition, 20 coleoptile lengths can be measured from 20 seeds as an AG indicator, whereas only one survival rate can be calculated from 20 seeds in the flooded soil evaluation method. We found that IR64 is moderately AG-tolerant (Fig. 3), although it is considered to be sensitive (Angaji et al. 2010, Baltazar et al. 2014, Kretzschmar et al. 2015, Miro and Ismail 2013). Thus, the anoxic water evaluation method has a higher resolution of AG phenotyping than the soil evaluation method.

It is laborious to dry a large amount of soil, sieve it and sow seeds carefully at the same depth. Moreover, flooded soil evaluation needs a large experimental space. On the other hand, anoxic water evaluation uses little space. We evaluated 104 lines in flooded soil evaluation by using a big container $(508.9 \mathrm{~L})$. On the other hand, we evaluated 54 lines in anoxic water evaluation by using a stainless-steel tray $(8.6 \mathrm{~L})$. Therefore, the experimental space could be reduced to approximately $1 / 30$ for one sample. Additionally, the incubation time in anoxic water evaluation is 5 to 7 days, whereas that in flooded soil evaluation is about 21 days, which means experimental time could be reduced to approximately $1 / 3$. These advantages make anoxic water evaluation suitable for the genetic analysis of many samples. However, we have to pay attention to the possibility of other stress exerted in this anoxic water.

Among ecotypes, $O$. sativa $\operatorname{Tr} \mathrm{J}$ tended to be more tolerant than $O$. sativa Aus and O. glaberrima (Fig. 4C). O. sativa TeJ was more AG tolerant than TrJ_I (Fig. 5B), although the accession number was small (TeJ, $\mathrm{n}=16, \mathrm{TrJ}$, $\mathrm{n}=6$ ). Thus, there is possibility that TeJ is most AG tolerant among these ecotypes. In addition, average length of coleoptiles of japonica varieties under anoxic condition were longer than those of indica varieties. Hsu and Tung (2015) reported that coleoptiles of japonica varieties tended to elongate faster than those of indica varieties in sterilized water. Our results showed similar trends with them. The coleoptiles of seven of the eight $O$. glaberrima accessions did not elongate under anoxic condition (Fig. 4B). In Africa, productive lowland NERICA ( to gain favour (Sie et al. 2008). However, most lowland NERICAs are derived from IR64 $\times O$. glaberrima 'TOG 5681', and our results shows the possibility that most lowland NERICAs do not have AG tolerance. The anoxic water evaluation method could be used in breeding to improve the AG tolerance of lowland NERICAs in further cross breeding with other sources of AG tolerant lines.

AG is a complex trait affected by seed dormancy, matu- ration, and storage conditions, so the isolation of genes responsible for AG has been difficult. Because anoxic water evaluation makes it easy to determine AG tolerance, it will greatly reduce the time for detecting AG QTLs, for isolation of the genes responsible, and for elucidation of its biological mechanisms.

\section{Author Contribution Statement}

NK, JS and TY designed the study, performed experiments, interpreted data and wrote the manuscript. KI performed experiments and interpreted data. RV interpreted data and reviewed the manuscript. All authors read and agreed on the final version of the paper.

\section{Acknowledgments}

This study was supported by the 'Rapid Mobilization of Alleles for Rice Cultivar Improvement in Sub-Saharan Africa' project of the Bill and Melinda Gates Foundation (Grant Number OPP1080832) to AfricaRice. We thank the IRRI Genebank and NARO Genebank for providing rice seeds. We are grateful to Masako Takahashi, Momoe Iizumi, Makiko Suzuki and Satomi Shimizu for their support.

\section{Literature Cited}

Alpi,A. and H. Beevers (1983) Effects of $\mathrm{O}_{2}$ concentration on rice seedlings. Plant Physiol. 71: 30-34.

Angaji, S.A. (2008) Mapping QTLs for submergence tolerance during germination in rice. Afr. J. Biotechnol. 7: 2551-2558.

Angaji, S.A., E.M. Septiningsih, D.J. Mackill and A.M.Ismail (2010) QTLs associated with tolerance of flooding during germination in rice (Oryza sativa L.). Euphytica 172: 159-168.

Atwell, B., I. Waters and H. Greenway (1982) The effect of oxygen and turbulence on elongation of coleoptiles of submergence-tolerant and-intolerant rice cultivars. J. Exp. Bot. 33: 1030-1044.

Baltazar, M.D., J.C.I. Ignacio, M.J.Thomson, A.M.Ismail, M.S. Mendioro and E.M. Septiningsih (2014) QTL mapping for tolerance of anaerobic germination from IR64 and the aus landrace Nanhi using SNP genotyping. Euphytica 197: 251-260.

Diagne,A., D.Y.Alia, E.Amovin-Assagba, M.C.Wopereis, K. Saito and T. Nakelse (2013) Farmer perceptions of the biophysical constraints to rice production in sub-Saharan Africa, and potential impact of research. Realizing Africa's rice promise, CABI, pp. 46-68

Ebana, K., Y. Kojima, S. Fukuoka, T. Nagamine and M. Kawase (2008) Development of mini core collection of Japanese rice landrace. Breed. Sci. 58: 281-291.

Ebana, K., J.-i. Yonemaru, S. Fukuoka, H. Iwata, H. Kanamori, N. Namiki, H.Nagasaki and M.Yano (2010) Genetic structure revealed by a whole-genome single-nucleotide polymorphism survey of diverse accessions of cultivated Asian rice (Oryza sativa L.). Breed. Sci. 60: 390-397.

Ella, E.S., M.L. Dionisio-Sese and A.M. Ismail (2010) Proper management improves seedling survival and growth during early flooding in contrasting rice genotypes. Crop Sci. 50: 1997-2008.

Guglielminetti,L., J. Yamaguchi, P. Perata and A.Alpi (1995) Amylolytic activities in cereal seeds under aerobic and anaerobic conditions. Plant Physiol. 109: 1069-1076. 
Hsu, S.K. and C.W.Tung (2015) Genetic mapping of anaerobic germination-associated QTLs controlling coleoptile elongation in rice. Rice (N Y) 8: 38.

Hsu, S.K. and C.W.Tung (2017) RNA-Seq Analysis of diverse rice genotypes to identify the genes controlling coleoptile growth during submerged germination. Front. Plant Sci. 8: 762.

Ismail,A.M., E.S. Ella, G.V.Vergara and D.J. Mackill (2009) Mechanisms associated with tolerance to flooding during germination and early seedling growth in rice (Oryza sativa). Ann. Bot. 103: 197209.

Kojima, Y., K. Ebana, S. Fukuoka, T. Nagamine and M. Kawase (2005) Development of an RFLP-based rice diversity research set of germplasm. Breed. Sci. 55: 431-440.

Kretzschmar,T., M.A. Pelayo, K.R. Trijatmiko, L.F. Gabunada, R.Alam, R. Jimenez, M.S. Mendioro, I.H. Slamet-Loedin, N. Sreenivasulu, J. Bailey-Serres et al. (2015) A trehalose-6-phosphate phosphatase enhances anaerobic germination tolerance in rice. Nat. Plants 1: 15124.

Meng, L., H.Li, L.Zhang and J.Wang (2015) QTL IciMapping: Integrated software for genetic linkage map construction and quantitative trait locus mapping in biparental populations. Crop J. 3: 269283.

Miro, B. and A.M.Ismail (2013) Tolerance of anaerobic conditions caused by flooding during germination and early growth in rice
(Oryza sativa L.). Front. Plant Sci. 4: 269.

Murray, M.G. and W.F.Thompson (1980) Rapid isolation of high molecular weight plant DNA. Nucleic Acids Res. 8: 4321-4326.

Nagata, K., T.Ando, Y.Nonoue, T.Mizubayashi, N. Kitazawa, A. Shomura, K. Matsubara, N. Ono, R. Mizobuchi, T. Shibaya et al. (2015) Advanced backcross QTL analysis reveals complicated genetic control of rice grain shape in a japonica $\times$ indica cross. Breed. Sci. 65: 308-318.

Perata,P., L. Guglielminetti and A.Alpi (1997) Mobilization of endosperm reserves in cereal seeds under anoxia. Ann. Bot. 79: 49-56.

Septiningsih, E.M., J.C. Ignacio, P.M. Sendon, D.L. Sanchez, A.M. Ismail and D.J.Mackill (2013) QTL mapping and confirmation for tolerance of anaerobic conditions during germination derived from the rice landrace Ma-Zhan Red. Theor. Appl. Genet. 126: 13571366.

Sie, M., Y. Sere, S. Sanyang, L.T.Narteh, S. Dogbe, M.M.Coulibaly, A.Sido, F.Cisse, E. Drammeh, S.A. Ogunbayo et al. (2008) Regional yield evaluation of the interspecific hybrids $(O$. glaberrima $\times O$. sativa) and intraspecific (O. sativa $\times$ O. sativa) lowland rice. Asian J. Plant Sci. 7: 130-139.

Zhang, M., Q.Lu, W.Wu, X.Niu, C.Wang, Y.Feng, Q.Xu, S.Wang, X. Yuan, H. Yu et al. (2017) Association mapping reveals novel genetic loci contributing to flooding tolerance during germination in indica rice. Front. Plant Sci. 8: 678. 